\title{
PERJUANGAN PEREMPUAN DALAM NOVEL PARA PAWESTRI PEJUANG KARYA SUPARTO BRATA DAN NOVEL GOD'S CALLGIRL KARYA CARLA VAN RAAY (KAJIAN SASTRA BANDINGAN)
}

\author{
Farahanna Juliani \\ Universitas Negeri Surabaya \\ julianifarah27@gmail.com
}

ABSTRAK

ABSTRACT
Novel Para Pawestri Pejuang karya Suparto Brata dan novel God's Callgirl karya Carla Van Raay memiliki kemiripan dalam bentuk perjuangan perempuan. Kedua novel tersebut akan dibedah menggunakan teori feminis liberal dari Naomi Wolf dan teori kajian sastra bandingan afinitas dari Suripan Sadi Hutomo. Fokus penelitian ini adalah bagaimana peran dan kedudukan perempuan dibidang ekonomi, penyampaian aspirasi dan berumah tangga dalam kedua novel tersebut. Tujuan penelitian ini untuk mengetahui bentuk peran dan kedudukan perempuan dibidang ekonomi, penyampaian aspirasi dan berumah tangga. Metode yang digunakan dalam penelitian ini adalah metode deskriptif kualitatif, instrumen penelitian adalah peneliti itu sendiri, teknik pengumpulan data menggunakan teknik pustaka, teknik analisis data menggunakan teknik deskriptif, dan menggunakan teknik triangulasi waktu untuk teknik pengujian keabsahan data. Hasil penelitian menyatakan terdapat perbedaan bentuk perjuangan dibidang ekonomi, penyampaian aspirasi dan berumah dikarenakan faktor budaya yang mempengaruhinya yaitu budaya Jawa dan budaya Australia.

Kata Kunci: peran, kedudukan, feminisme, sastra bandingan

Para Pawestri Pejuang by Suparto Brata and God's Callgirl by Carla Van Raay have a woman struggle similarities form. The novels will be dissected using the liberal feminist theory by Naomi Wolf and comparative literature study of affinity by Suripan Sadi Hutomo. The focus of this research is to know how form of woman's role and position in the economy's field, woman's aspiration delivery and woman's life after married. The purpose of this research is to know woman's role and position in the economy's field, woman's aspiration's delivery and woman's life after married. The method in this research is qualitative descriptive, the research instrument is the researcher itself, data collection techniques is library techniques, data analysis techniques is descriptive techniques, and using time triangulation techniques for testing techniques of data validity. . The result of the research stated that the novel's have different economic struggle's form, woman aspiration's delivery, and woman's life after married because they have different cultural, Javanese and Australian culture.

Keywords: role, position, feminism, comparative literature 
PENDAHULUAN Perjuangan perempuan merupakan topik yang menarik perhatian karena topik ini dapat memberikan pengetahuan untuk para pembaca agar pembaca dapat mengerti jika perjuangan perempuan untuk menuntut kebebasan dan persamaan hak sangat penting khususnya bagi para perempuan yang menjadi kaum terpingirkan. Novel Para Pawestri Pejuang karya Suparto Brata ini sangat menarik dan unik dibandingkan novel-novel lainnya karena menggambarkan perjuangan perempuan baik dalam segi ekonomi hingga perjuangan perempuan dalam kehidupan berumah tangga ditengah kungkungan budaya Jawa yang harus dijunjung tinggi oleh seorang perempuan Jawa. Topik mengenai perjuangan perempuan juga diceritakan dalam novel God's Callgirl karya Carla Van Raay. Karya Carla Van Raay lebih berani mengungkapkan kebebasan perempuan. Novel ini sangat menarik karena novel ini menggambarkan perjuangan kaum perempuan dengan cara yang berbeda dan hal tersebutlah yang membuat novel ini unik. Ada babbab yang menarik perhatian dalam kedua novel tersebut yaitu terdapat kemiripan dalam kedua novel tersebut dan hal tersebutlah yang mendasari kedua novel tersebut layak untuk dibandingkan.

Selain terdapat kemiripan tersebut, juga terdapat perbedaan pada kedua novel tersebut. Cara penyampaian perjuangan perempuan oleh kedua pengarang novel tersebut sangat berbeda. Hal tersebut dipengaruhi oleh latar belakang budaya yang dimiliki penulis. Perjuangan kaum perempuan merupakan bentuk gerakan feminisme.

Feminisme itu sendiri adalah gerakan untuk menolak segala bentuk perendahan kaum perempuan oleh kebudayaan yang ada seperti dalam politik, ekonomi, sosial, dan budaya (Ratna, 2013:84). Faktor utama yang menyebabkan adanya gerakan feminisme

adalah banyaknya masyarakat yang meremehkan perempuan. Perempuan hanya menjadi objek yang tidak bisa memiliki kebebasan dalam berfikir dan menyampaikan pendapat. Penelitian feminisme berusaha memahami kedudukan dan peran perempuan (Sugihastuti dan Suharto, 2015:15). Hal tersebut juga dipertegas oleh Endraswara (2013:146). Menurut Soekanto (2012:213) peranan (role) merupakan aspek dinamis kedudukan (status). Menurut Soekanto (2012:210-211) kedudukan diartikan sebagai tempat atau posisi seseorang dalam suatu kelompok sosial. Gamble (2010:3) menyatakan benar tidaknya kegiatan perjuangan kaum perempuan untuk dapat memperoleh prilaku yang lebih baik dari kaum pria kegiatan tersebut tetap disebut kegiatan feminisme.

Fakih (1997:63) memaparkan bahwa perempuan sering kali mengalami penindasan dan dijadikan bahan ekspolitasi sehingga segala bentuk kegaiatan untuk melawan itu semua disebut kegiatan feminisme. Perempuan harus memperjuangkan haknya karena hal tersebut merupakan masalah kemanusiaan (Gadis dkk., 2003:45). Feminisme berkembang di Barat tepatnya di Eropa dan Amerika Serikat namun bukan merupakan gerakan yang homogen (Saptari, 1997:47). Humm memaparkan bahwa feminisme menggabungkan 
doktrin mengenai persamaan hak perempuan yang selanjutnya menjadi gerakan yang terorganisasi untuk menuntut hak asasi perempuan (Wiyatmi, 2012:10). Djajanegara (2000:19) mengatakan bahwa feminisme ada karena adanya aspek-aspek lain yang mempengaruhi seperti faktor agama, sosial, dan persamaan hak. Beauvoir menyatakan bahwa perempuan yang menikah adalah perempuan yang telah menjadi budak (Tong, 2008:262). Feminitas tidak sekadar merupakan penerimaan pasif oleh perempuan atas dominasi patriarki, feminitas berubah didalam dan melawan hegemoni (Thornham, 2010:117). Saptari (1997:47) menyatakan bahwa feminisme gelombang kedua yang berkembang tahun pada tahun 1960-an dan menghasilkan tiga pendekatan utama yaitu pendekatan radikal, liberal, dan sosialis. Dari ketiga pendekatan tersebut, pendekatan yang paling cocok dengan penelitian ini adalah pendekatan liberal. Gamman dan Marshment (2010:49) menyatakan bahwa dalam feminisme liberal maka perempuan harus direpresentasikan secara adil. Agger (2013:215) menyatakan bahwa feminisme liberal berpandangan bahwa perempuan dapat menaikkan posisi mereka dalam keluarga dan masyarakat melalui kombinasi inisiatif dan prestasi individual. Naomi Wolf adalah tokoh feminisme liberal. Menurut Wolf (1993:34-35) terdapat 2 pelajaran tentang feminisme. Pelajaran pertama adalah saat perempuan menyuarakan pendapat dan terdapat perubahan. Pelajaran kedua adalah perempuan harus memiliki uang dan menggunakan uang.

Feminisme sering juga disebut kesetaraan, adanya feminisme menyebabkan munculnya istilah kesetaraan gender. Mosse mengemukakan bahwa untuk menyampaiakan bahwa kita laki-laki atau perempuan sama halnya seperti pemakaian baju atau kostum dan juga topeng dalam sebuah pertunjukan (Darni, 2015:25). Wiyatmi (2012:xv) menyatakan jika gender adalah sifat dan identitas yang dianggap cocok dengan jenis kelaminnya, gender dibentuk secara sosial dan dipengaruhi oleh unsur budaya. Perlu adanya pemaknaan melalui kesadaran sosial bahwa gender terbentuk melalui proses sejarah dan budaya yang panjang (Mufidah, 2004:9). Handayani (2004:vii) menyatakan bahwa kata perempuan atau wanita berasal dari kata wani dan tapa. Kartono (2006:16) menyatakan bahwa sifat khusus perempuan Jawa ada tiga, yaitu indah, halus, dan berhati rendah. Sedangkan perempuan Australia digambarkan sebagai masyarakat yang demokratis sehingga akses perempuan terhadap proses demokrasi melalui kewarganegaraan aktif. Terdapat sebuah organisasi yang bernama Women's Forum Australia (WFA) yang concern terhadap pendidikan (edukasi) dan perkembangan kebijakan publik tentang sosial, ekonomi, kesehatan serta isu-isu kultural yang berkenaan dengan permasalahan perempuan di Australia (Endarsih, 2015:5). Australia juga memiliki keyakinan yang teguh bahwa tidak ada orang yang boleh ditindas karena adanya perbedaan hanya karena berbeda latar belakangnya (Yuwono, 2015:3). 
Selain menggunakan feminisme untuk meneliti kedua novel tersebut, peneliti juga menggunakan ilmu sastra bandingan untuk meniti kedua novel tersebut. Comparative literature atau la litterature comparee merupakan istilah lain dari sastra bandingan (Hutomo, 1993:128). Damono (2009:1-2) memaparkan satusatunya ilmu sastra yang tidak menghasilkan teori tersendiri adalah ilmu sastra bandingan. Endraswara (2013:128) juga menyatakan jika sastra bandingan adalah daerah sastra yang memaparkan hubungan karya sastra satu dengan bidang sastra lainnya. Stallknecht dan Frenz (1990:5) memaparkan bahwa perhatian dari satra bandingan adalah kajian sastra bandingan yang bisa menumbuhkan kesatuan penghayatan bagi peneliti.

Hutomo (1993:3) melihat praktek sastra bandingan di negara Barat dan Timur maka sastra bandingan melandaskan diri pada afinitas, tradisi, dan pengaruh. Penelitian ini menggunakan teori bandingan afinitas atau affinity untuk mengungkapkan atau membedah bentuk perjuangan perempuan sehingga dapat memperoleh perbedaan dan persamaan bentuk perjuangan perempuan. Nurgiyantoro (2007:37) mengatakan bahwa kegiatan analisis dilakukan dengan cara mengidentifikasi, mengkaji, dan menjelaskan unsur-unsur atau motif-motif yang ada dalam dua novel. Jadi, analisis yang dianggap cocok dengan kajian sastra bandingan yaitu analisis struktur.

Motif-motif yang ada dalam dua novel tersebut adalah motif ekonomi, beraspirasi, dan berumah tangga. Ilmu ekonomi merupakan salah satu cabang ilmu sosial yang menaruh perhatian pada masalah bagaimana seharusnya memanfaatkan sumber daya yang jumlahnya terbatas untuk memenuhi kebutuhan manusia yang beraneka ragam dan tidak terbatas (Multifah, 2011:1). Timbulnya masalah pokok ekonomi adalah karena adanya kesenjangan antara sumber daya-sumber daya dengan kebutuhan manusia (Bangun, 2014:3). Menurut Haryanto (2008:216-218) pada sisi ekonomi rumah tangga miskin telah memaksa mereka untuk melakukan pengoptimalan pendapatan melalui pengerahan sumber daya ekonomi yang dimiliki. Keikutsertaan perempuan dalam mencari nafkah akan membawa dampak positif yaitu adanya peningkatan terhadap struktur sosial dalam keluarga (Puspitasari dkk, 2013:11). Menurut Putri dan Lestari (2015:72-75) ketika memasuki kehidupan pernikahan, laki-laki dan perempuan memiliki peran baru yang merupakan konsekuensi dari pernikahan. Salah satu hak warga negara sebagaimana yang dinyatakan adalah kebebasan dan kemerdekaan. Dengan menyurakan aspirasi mereka tentang HAM, perempuan menginginkan penghapusan deksriminasi yang saat ini melekat pada sosok perempuan (Arifianie, 2014:1).

Fokus dan tujuan umum penelitian ini adalah perjuangan perempuan dalam novel Para Pawestri Pejuang karya Suparto Brata dan novel God's Callgirl karya Carla Van Raay. Fokus umum tersebut dapat dirumuskan secara khusus ke dalam tiga hal berikut: (1) Peran dan kedudukan perempuan dibidang ekonomi dalam novel Para Pawestri Pejuang karya Suparto Brata dan novel 
God's Callgirl karya Carla Van Raay. (2) Peran dan kedudukan perempuan dibidang penyampaian aspirasi dalam novel Para Pawestri Pejuang karya Suparto Brata dan novel God's Callgirl karya Carla Van Raay. (3) Peran dan kedudukan perempuan dibidang rumah tangga dalam novel Para Pawestri Pejuang karya Suparto Brata dan novel God's Callgirl karya Carla Van Raay.

\section{METODE}

PEMBAHASAN

Penelitian ini menggunakan desain penelitian kualitatif. Peneliti menggunakan pendekatan kualitatif untuk memaparkan hasil analisis. Menurut Siswantoro (2010:57), penelitian sastra dalam metode deskriptif kualitatif dituntut untuk memaparkan fakta-fakta yang terdapat dalam karya sastra dengan cara memberikan deskripsi. Penelitian ini menggunakan sumber data novel Para Pawestri Pejuang karya Suparto Brata yang diterbitkan tahun 2013 di Yogyakarta oleh Elmatera dan novel ini memiliki 196 halaman. Sedangkan Novel God' Callgirl karya Carla van Raay diterbitkan tahun 2006 di Amerika oleh Harper Collins dan novel ini memiliki 508 halaman. Data primer dalam penelitian ini yaitu kedudukan dan peran perempuan di bidang ekonomi, berumah tangga, dan beraspirasi. Sedangkan artikel-artikel atau berita yang berhubungan dengan perempuan, karya sastra dan gerakan feminisme di Indonesia dan Australia merupakan data sekunder. Instrumen penelitian adalah peneliti itu sendiri.

Menurut Jabrohim (2015:24) peneliti ketika melakukan penelitian harus memiliki pikiran yang kritis. Tata cara pengumpulan data disini adalah membaca karya sastra dan mengerti adanya masalah yang ada dalam karya sastra itu sendiri, mengidentifikasi masalah, menentukan alat untuk mengupas fokus penelitian seperti menentukan pendapat ahli yang dianggap cocok untuk memecahkan masalah, inventarisasi, membuat simpulan. Penelitian ini menggunakan teknik analisis deskriptif untuk mendeskripsikan data yang menjadi objek kajian dan dikutip secara langsung. Lebih lanjut Cresweell (2012:276) memaparkan teknik analisis data penelitian ini adalah mengolah dan mempersiapkan data, membaca data yang telah didapat, menganalisis lebih detail dengan men-coding data, menerapkan proses coding, menunjukkan bagaimana deskripsi dari fokus penelitian yang akan disajikan kembali ke dalam bentuk narasi/laporan kualitatif, membuat tabel perbandingan, menginterpretasikan atau memaknai data. Peneliti disini menggunakan teknik triangulasi waktu untuk menguji keabsahan data. Teknik ini untuk menilai kecocokan data berdasarkan pada cara pengumpulan data atau prosedur pengumpulan data (Sugiyono, 2010:271).

Terdapat persamaan dan perbedaan diantara novel Para Pawestri Pejuang dan God's Callgirl yaitu sama-sama memperjuangkan hak perempuan dibidang ekonomi, beraspirasi, dan berumah tangga. 
Peran dan kedudukan perempuan di bidang ekonomi dalam novel Para Pawestri Pejuang karya Suprto Brata dan God's Callgirl karya Carla Van Raay

a. Peran dan Kedudukan Perempuan di bidang Ekonomi dalam Novel Para Pawestri Pejuang karya Suprto Brata

1) Wara Pramesthi yang memikirkan perekonomian negarnya

Wara Pramesthi adalah wanita yang berpendidikan. Dia sangat pintar dalam memanfaatkan kepintarannya, siapa saja yang menjadi lawannya selalu terkesima dengan pola pikirnya termasuk bosnya. Apapun yang diinginkan Wara untuk mengatur perusahannya pasti disetujui oleh bosnya dengan diberikannya kepercayaan yang tinggi oleh bosnya. Para Pawestri Pejuang merupakan novel yang berlatar belakang tahun 90-an. Berlatar belakang orde lama. Ketika jaman tersebut, kedudukan dan peran wanita sangat minim karena wanita sangat dibatasi gerakgeriknya. Namun berbeda dengan Wara Pramesthi yang ketika jaman tersebut dia telah menjadi wanita yang sangat berpengalaman dalam bidang ekonomi.

"Up to you, dear! You are what you are, you are the best. Pretty girls wis percaya banget marang kowe," ujare Si Bule marang Wara Pramesthi (Brata, 2013:13).

"Kantorku wis percaya karo aku. Apa tindakanku wis mesthi bener," tuture Wara Pramesthi marang Ngesthiratu (Brata, 2013:87).

Wara Pramesthi sebagai perempuan yang dipercaya oleh bosnya, apalagi bosnya bukan orang pribumi tetapi orang Amerika. Semua yang menjadi kemauan dan keputusan Wara pasti didukung penuh oleh bosnya. Wara ingin agar orang asing berinvestasi di Indonesia sehingga dia bekerja keras agar bosnya percaya dengannya. Wara berpikir jika orang asing berinvestasi di Indonesia maka akan mengangkat perekonomian Indonesia yang pada saat itu sedang krisis moneter. Bisa disimpulkan bahwa Wara Pramesthi memiliki kedudukan yang tinggi di perusahannya sehingga atasannya mempercayakan semuanya pada Wara. Wara sendiri memiliki peran yang sangat penting bagi Indonesia karena mampu membuat investor asing sepeti bosnya mau berinvestasi di Indonesia yang pada saat itu sedang krisis moneter.

b. Peran dan kedudukan perempuan di bidang ekonomi dalam novel God's Callgirl karya Carla Van Raay

Carla adalah seorang perempuan yang bekerja di sebuah restoran dengan gaji yang sangat pas-pasan sementara dirinya memiliki satu anak perempuan yang masih kecil untuk terus dihidupinya. Dia merasakan bahwa pekerjaannya sebagi pelayan restoran tidaklah mempu mencukupi kehidupannya 
dan anaknya sehingga diamemiliki keinginan untuk bekerja ditempat lain dengan gaji yang lebih besar.

"I would do better, I told myself. I would prostitute my body for good money and have fun, as well” (Van Raay, 2004:292).

Kutipan diatas menyatakan bahwa Carla rela menjual tubuhnya demi kehidupan yang lebih baik yaitu demi mendapatkan uang yang lebih banyak untuk membiayai kehidupannya dan anaknya. Dia berjuang bagaimana agar hidup anaknya layak dan tidak kekurangan. Carla disini berperan sebagi ibu yang sangat memperjuangkan anaknya terbukti dengan dirinya yang rela menjadi seorang wanita malam. Dia juga memiliki kedudukan yang penting dalam keluarganya karena tanpa perjuangannya maka tidak akan ada kehidupan yang layak untuk anaknya yang masih kecil.

Peran dan kedudukan perempuan di bidang penyampaian aspirasi dalam novel Para Pawestri Pejuang karya Suparto Brata dan God's Callgirl karya Carla Van Raay

a. Peran dan kedudukan perempuan di bidang penyampaian aspirasi dalam novel Para Pawestri Pejuang karya Suparto Brata

1) Ngesthiratu yang berani beraspirasi

Ngesthiratu adalah wanita muda berumur 17 tahun yang sangat baik dalam beraspirasi apalagi ketika membahas mengenai keadaan negaranya, Indonesia. Pada jaman tersebut, kebebasan wanita sangat dibatasi dengan sangat tegas oleh pemerintah. Banyak masyarakat yang dipenjara bahkan dibunuh ketika tidak sejalan dengan pemerintah. Namun hal tersebut tidak mempengaruhi Ngesthiratu dalam menyampaikan aspirasinya.

"Aku rak ya generasi enom, ta, Bu. Kepengin ngreti obahe jaman. Ya mumpung bisa mlaku nyekseni sarana mripat mlolo, ya dakperlokake pisan ndeleng geger ing punjere perubahan jaman” (Brata, 2013:19).

Ibu sangat mengkhawatirkan anak perempuannya yang sangat berani beraspirasi apalagi anaknya masih SMA dan sudah ikut memikirkan keadaan negaranya dan langsung datang ke tempat demonstrasi. Peran Ngesthiratu dalam keluarganya sangat jelas yaitu perempuan muda yang sangat kuat keinginannya untuk beraspirasi walaupun ditentang oleh keluarganya. Kedudukan dalam keluarganya juga sangat jelas bahwa dia adalah anak yang sangat disayangi oleh keluarganya terutama ibunya.

b. Peran dan kedudukan perempuan di bidang penyampaian aspirasi dalam novel God's Callgirl karya Carla Van Raay 
Carla disini memiliki pikiran yang sangat luar biasa tentang Tuhan dan kehidupan. Semua yang ingin dia tahu maka akan dia tanyakan dan akan dia cari tahu. Dia juga tidak takut untuk menyammpaikan pendapat maupun pertanyaan dan juga tidak takut melakukan hal yang dianggapnya baik dan membuatnya jauh lebih baik juga.

"Blind Obedience, where a sister took no responsibility for her own actions in her efforts to do the will of God by simply following commands, was no longer acceptable to the spirit of reform" (Van Raay, 2004:227).

Kutipan diatas menyatakan salah satu pendapat Carla tentang kehidupan seorang biarawati/suster yang hanya mengikuti perintah Tuhannya. Pendapat Carla tersebut sangat berani karena hal tersebut menyangkut sebuah agama yang dianggap sakral. Carla berjuang mencari arti tentang Tuhan dan segalah hal yang berhubungan tentang hal tersebut. Carla memiliki peran sebagai wanita yang berkeinginan menjadi seorang suster dengan segala ketidaktahuannya demi bangkit dan mencari kedamaian dan hakekat Tuhan yang sebenarnya.

\section{Peran dan kedudukan perempuan di bidang berumah tangga dalam novel Para Pawestri Pejuang karya Suparto Brata dan God's Callgirl karla Carla Van Raay}

a. Peran dan kedudukan perempuan di bidang rumah tangga dalam novel Para Pawestri Pejuang karya Suparto Brata

1) Pembayun Ratri berjuang demi keutuhan keluarganya

Pembayun Ratri sangat menyayangi suaminya sehingga apapun yang membuat suaminya bahagia pasti dilakukannya. Dia rela suaminya senang walaupun kesenangan tersut tidak datang darinya dan bahkan membuatnya sakit. Pambayun Ratri mengikhlaskan suaminya untuk orang lain agar suaminya mendapatkan kepuasaan yang tidak bisa didapatkana darinya. Hal tersebut dilakukannya karena dirinya merupakan wanita lumpuh semenjak mengalami kecelakaan kerja. Pembayun Ratri memang perempuan yang ikhlas mengorbankan perasaannya untuk keutuhan keluarganya.

“Ora, Ra. Ora. Yen prekara kuwi, aku ora sedhih. Wiwit lumpuh sepuluh taun kepungkur, aku wis eklas ngeculake bapakmu njajan wong wadon liya. Aku ora nesu lan buterapan nalika bapakmu srawung rapet karo Monica, apa Solikah, apa karo sekretaris kantore. Malah aku melu ngrasa seneng yen bapakmu crita beres anggone dhemenan karo Carla Maramis. Bapakmu rak senengane karo praupan indo ngana kae” (Brata, 2013:31). 
Kutipan di atas menggambarkan bahwa pembayun Ratri berjuang untuk keutuhan keluarganya agar dirinta tidak menjadi benalu di keluarga yang sangat dia sayangi tersebut. Peran dan kedudukan Pembayun Ratri dalam novel tersebut sangatlah terlihat. Pembayun Ratri berperan menjadi ibu rumah tangga yang sangat baik menjaga keutuhan keluarganya meski hal tersebut menyakiti dirinya sendiri. Kedudukannya juga sangat penting dalam keluarga, tanpa perjuangannya keluarganya tidak akan menjadi keluarga yang utuh seperti sekarang ini.

b. Peran dan kedudukan perempuan di bidang berumah tangga dalam novel God's Callgirl karya Carla Van Raay

Carla menikah dengan seorang laki-laki yang bernama James. Bagi Carla James adalah laki-laki yang tidak tahu bagaimana menjadi seorang suami bagi seorang perempuan. James selalu setuju dengan apa yang dilakukan Carla. James tidak memiliki kehendak yang kuat dan semuanya bergantung pada Carla dan hal itulah yang membuat Carla dalam kesalahan besar.

James and I lost all of our saving to Golden Products. It was this that made him decide to head for the north of Western Australia, to work as an electrical engineer for good money. I was to be a temporary housekeeper in Perth until the baby was due" (Van Raay, 2004:283).

Carla menerima apa adanya James. Dia berjuang menjadi kepala rumah tangga karena suaminya (James) tidak bisa diandalkan. Semua dia hadapi demi keutuhan rumah tangganya. Dia rela tetap bersama James walaupun James tidak beruang dan hanya bekerja sebagai tukang listrik. James dan Carla juga harus ditinggal berjauhan saat Carla membutuhkan James untuk menemaninya ketika dia hamil anak James. Carla rela tidak mendapatkan itu semua dari James dan merelakan James bekerja jauh darinya. Peran Carla di sini adalah sebagai istri yang baik, menerima keadaan suaminya dan mau berbagi tugas dengan suaminya. Kedudukan Carla di sini juga sangat penting karena tanpa adanya rasa ikhlas Carla untuk menerima James apa adanya maka rumah tanggan tidak akan utuh.

\section{SIMPULAN}

Penelitian ini membahas tentang perjuangan perempuan dalam novel Para Pawestri Pejuang karya Suparto Brata dan novel God's Callgirl karya Carla Van Raay. Kedua novel tersebut dikaji dengan menggunakan teori feminisme liberal dari Naomi Wolf yang berpendapat bahwa perempuan harus berani berpendapat dan membuat perubahan serta harus memiliki uang dan menggunakannya. Kedudukan dan peran juga harus diteliti untuk mengupas gerakan feminisme itu sendiri. Hal tersebutlah yang membuat rumusan masalah dalam penelitian ini membahas kedudukan dan peran perempuan. Selain itu, penelitian ini juga 
menggunakan teori sastra bandingan afinitas dari Suripan Sadi Hutomo untuk membandingkan kedua novel tersebut.

Novel tersebut sangat unik sehingga layak untuk dibandingkan karena memiliki bab yang sama yaitu tentang bentuk perjuangan perempuan. Kedua novel tersebut juga memiliki banyak perbedaan diantaranya bentuk perjuangan perempuan yang dipengaruhi latar belakang budaya pengarang yang berbeda. Hasil penelitian menyatakan bahwa kedua novel tersebut sama-sama membahas bentuk perjuangan perempuan di bidang ekonomi, beraspirasi, dan berumah tangga.

\section{DAFTAR PUSTAKA}

Agger, Ben, 2013. Mazhab Frankfurt Karl Max Cultural Studies Teori Feminisme Derrida Posmodernitas; Teori Sosial Kritis. Yogyakarta: Kreasi Wacana Yogyakarta.

Arikunto, Suharsini. 2010. Prosedur Penelitian Suatu Pendekatan Praktik. Jakarta: PT Rineka Cipta.

Brata, Suparto. 2013. Para Pawestri Pejuwang. Yogyakarta: Elmatera.

Bangun, Wilson. 2014. Teori Ekonomi Mikro. Bandung: PT. Rafika Aditama.

Creswell, John W. 2012. Research Design; Pendekatan Kualitatif, Kuantitatif,dan Mixed. Yogyakarta: Pustaka Pelajar.

Darni. 2015. Kekerasan Terhadap Perempuan Dalam Fiksi Jawa Modern. Surabaya: Penerbit Bintang Surabaya.

Damono, Sapardi Djoko. 2009. Sastra Bandingan. Jakarta: Editum.

Djajanegara, Soenarjati. 2000. Kritik Sastra Feminis: Sebuah Pengantar. Jakarta: PT. Gramedia Pustaka Utama.

Pertama: Metodologi Penelitian Sastra. Yogyakarta: CAPS.
Endraswara, Suwardi. 2013. Metodologi Penelitian Sastra; Epistimologi, Model, Teori, dan Aplikasi. Jakarta: Caps.

Endarsih. I. 2015. Women's Forum di Australia Sebagai Gerakan Feminisme. (online). (httpeprints.umm.ac.id257852jipt ummpp-gdl-isnawatyen-38543-2bab1.pdf, diakses 1 Maret 2018).

Fakih, Mansour. 1997. Analisis Gender dan Transformasi Sosial. Yogyakarta: Pustaka Pelajar.

Frenz, Horst lan Ed. Newton P. Stallknecht. 1990. Sastra Perbandingan; Kaedah dan Perspektif. Kuala Lumpur: Percetakan Dewan Bahasa dan Pustaka.

Fromm, Erich. 2007. Cinta, Seksualitas dan Matriarki: Kajian Komprehensif Tentang Gender. Yogyakarta: Jalasutra.

Gadis, dkk. 2003. Jurnal Perempuan; Untuk Pencerahan dam Kesetaraan. Jakarta: Yayasan Jurnal Perempuan.

Gamman, Lorraine dan Margaret Marshment. 2010. Tatapan Perempuan; Perempuan sebagai Penonton Budaya Populer. Yogyakarta: Jalasutra. 
Gamble, Sarah. 2010. Pengantar Memahami Feminisme dan Postfeminisme. Yogyakarta: Jalasutra.

Handayani, Christina S. 2004. Kuasa Perempuan Jawa. Yogyakarta: Lkis.

Hollows, Joanne. 2010. Feminisme, Feminitas, dan Budaya Populer. Yogyakarta: Jalasutra.

Horton, Rosalind and Sally Simmons. 2006. Women Who Changed The World. London: Quercus Publishing Plc.

Hutomo, Saripan Sadi. 1993. Merambah Matahari; Sastra dalam Perbandingan. Jakarta: Gaya Masa.

Jabrohim. 1994. Teori Penelitian Sastra. Yogyakarta: Pustaka Pelajar.

Kartono, Kartini. 2006. Psikologi Perempuan 1: Mengenal Gadis Remaja dan Perempuan Dewasa. Bandung: Bandar Maju.

Mufidah. 2004. Paradigma Gender. Malang: Bayu Media.

Multifiah. 2011. Teori Ekonomi Makro. Malang: UB Press.

Nurgiyantoro, Burhan. 2007. Teori Pengkajian Fiksi. Yogyakarta: Gadjah Mada University Press.

Prabasmoro, Aquarini Priyatna. 2006. Kajian Budaya Feminis; Tubuh, Sastra, dan Budaya Pop. Yogyakarta: Jalasutra.

Prantiasih, Arbaiyah. 2012. Hak Asasi Manusia Bagi Perempuan. Volume 25 Nomor 1 Tahun 2012. (online) tersedia (journal.um.ac.id/index.php diakses pada 17/05/2018 12:27 WIB).
Puspitasari, dkk. 2013. Peran Gender, Kontribusi Ekonomi Perempuan, dan Kesejahteraan Keluarga Petani Hortikultura. Volume 6 Nomor 1 Tahun 2013. (online) tersedia

(jurnal.ipb.ac.id/index.pdf diakses pada 14/05/2018 14:16 WIB).

Putri, Dyah Purbasari Kusumaning dan Lestari Sri. 2015. Pembagian Peran Dalam Rumah Tangga Pada Pasangan Suami Istri di Jawa. Volume 16 Nomor 1 Tahun 2015. (online) tersedia (jurnal.ums.ac.id/index.pdf diakses pada 14/05/2018 15:11 WIB).

Ratna, Nyoman Kutha. 2013. Teori, Metodhe, dan Teknik Penelitian Sastra. Yogyakarta: Pustaka Belajar.

Saptari, Ratna fan Brigitte Holzner. 1997. Perempuan Kerja dan Perubahan Sosial. Jakarta. Grafiti Press.

Siswantoro. 2010. Metode Penelitian Sastra; Analisis Struktur Puisi. Yogyakarta: Pustaka Belajar.

Soekanto, Soerjono. 2012. Sosiologi Suatu Pengantar. Jakarta: PT. Raja Grafindo Persada.

Sugeng, Haryanto. 2008. Peran Aktif Wanita Dalam Peningkatan Pendapatan Rumah Tangga Miskin: Studi Kasus Pada Wanita Pemecah Batu Di Pucanganak Kecamatan Tugu Trenggalek. Vol 09 Nomor 02 Tahun 2008. (online) tersedia (media.neliti.com/media/publicati ons/83441-ID-peran-aktif-wanitadalam-peningkatan-pen.pdf, diakses pada 14/05/2018 14:09 WIB). 
Perjuangan Perempuan dalam Novel Para Pawestri Pejuang Karya Suparto Brata dan Novel God's Callgirl Karya Carla Van Raay (Kajian Sastra Bandingan)

Sugiyono. 2010. Metode Penelitian Kuantitatif Kualitatif dan $R \& D$. Alfabeta: Bandung.

Suharto dan Sugihastuti. 2013. Kritik Sastra Feminis: Teori dan Aplikasi. Yogyakarta: Pustaka Pelajar Offset.

Thornham, Sue. 2010. Teori Feminis dan Cultural Studies. Yogyajarta: Jalasutra.

Tong, Rosemarie Putnam. 1998. Feminist Thought: Pengantar Paling Komprehensif kepada Arus Utama Pemikiran Feminis. Bandung: Jalasutra.

Van Raay, Carla. 2004. God's Callgirl. Australia: Harper Collins Publisher.

Wiyatmi. 2012. Kritik Sastra Feminisme: Teori dan
Aplikasinya dalam Sastra Indonesia. Yogyakarta: Ombak.

Wolf, Naomi. 1993. Fire with Fire; The New Female Power and How It Will Change the 21st Century. Toronto: Random House of Canada.

Yuwono, Cynthia Alifia Putri. 2015. Tindak Degsiya Sajrone Novel Rembulan Dhuwur Blumbang Anggitane Sunarko Budiman lan Novel Runway Wife Angitane Margaret Way (Kajian Sastra Bandingan). Volume 03 Nomor 03 Tahun 2015. (online) tersedia (jurnalmahasiswa.unesa.ac.id.pdf, diakses pada 30/01/2018 16:47 WIB). 